\title{
Changes in Brain Function Occur Years before the Onset of Cognitive Impairment
}

\author{
Lori L. Beason-Held, ${ }^{1}$ Joshua 0. Goh, ${ }^{1,2}$ Yang An, ${ }^{1}$ Michael A. Kraut, ${ }^{3}$ Richard J. 0'Brien, ${ }^{4}$ Luigi Ferrucci, ${ }^{1}$ \\ and Susan M. Resnick ${ }^{1}$ \\ ${ }^{1}$ Intramural Research Program, National Institute on Aging, National Institutes of Health, Baltimore, Maryland 21224, ${ }^{2}$ Graduate Institute of Brain and \\ Mind Sciences, National Taiwan University College of Medicine, Taipei 100, Taiwan, ${ }^{3}$ Department of Radiology, Johns Hopkins Hospital, Baltimore, \\ Maryland 21287, and ${ }^{4}$ Department of Neurology, Johns Hopkins University School of Medicine, Baltimore, Maryland 21224
}

To develop targeted intervention strategies for the treatment of Alzheimer's disease, we first need to identify early markers of brain changes that occur before the onset of cognitive impairment. Here, we examine changes in resting-state brain function in humans from the Baltimore Longitudinal Study of Aging. We compared longitudinal changes in regional cerebral blood flow (rCBF), assessed by ${ }^{15} 0$-water PET, over a mean 7 year period between participants who eventually developed cognitive impairment $(n=22)$ and those who remained cognitively normal $(n=$ 99). Annual PET assessments began an average of 11 years before the onset of cognitive impairment in the subsequently impaired group, so all participants were cognitively normal during the scanning interval. A voxel-based mixed model analysis was used to compare groups with and without subsequent impairment. Participants with subsequent impairment showed significantly greater longitudinal rCBF increases in orbitofrontal, medial frontal, and anterior cingulate regions, and greater longitudinal decreases in parietal, temporal, and thalamic regions compared with those who maintained cognitive health. These changes were linear in nature and were not influenced by longitudinal changes in regional tissue volume. Although all participants were cognitively normal during the scanning interval, most of the accelerated $\mathrm{rCBF}$ changes seen in the subsequently impaired group occurred within regions thought to be critical for the maintenance of cognitive function. These changes also occurred within regions that show early accumulation of pathology in Alzheimer's disease, suggesting that there may be a connection between early pathologic change and early changes in brain function.

\section{Introduction}

It is estimated that as many as 5.4 million individuals are currently diagnosed with Alzheimer's disease (AD) in the United States alone, and this number is expected to triple by the year 2050. The marked increase in the number of people with AD has tremendous implications not only for an already overburdened healthcare system, but also for the individuals themselves and for their 15 million caretakers (Alzheimer's Association, 2012).

Current experimental treatments of $\mathrm{AD}$ revolve around reversing existing pathology in the brains of those already diagnosed with the disease, primarily focusing on $\beta$-amyloid removal (Callaway, 2012; Castellani and Perry, 2012). So far, however, the participants in these studies have not shown significant cognitive benefits related to the removal of $\beta$-amyloid.

\footnotetext{
Received April 2, 2013; revised Sept. 11, 2013; accepted Sept. 17, 2013.

Author contributions: M.A.K. and S.M.R. designed research; L.L.B.-H., M.A.K., R.J.O., L.F., and S.M.R. performed research; J.0.G. contributed unpublished reagents/analytic tools; L.L.B.-H., J.0.G., and Y.A. analyzed data; L.L.B.-H. wrote the paper.

This work was supported in part by the Intramural Research Program of the National Institutes of Health, National Institute on Aging, and Research and Development Contract N01-AG-3-2124. We thank the BLSA participants and staff for their dedication to these studies and the staff of the Johns Hopkins PET facility for their assistance.

The authors declare no competing financial interests.

Correspondence should be addressed to Dr. Lori Beason-Held, National Institute on Aging/LBN, 251 Bayview Boulevard, Baltimore, MD 21224-6825. E-mail: heldlo@mail.nih.gov.

DOI:10.1523/JNEUROSCI.1402-13.2013

Copyright $\odot 2013$ the authors $\quad 0270-6474 / 13 / 3318008-07 \$ 15.00 / 0$
}

In $\mathrm{AD}$, abnormal accumulation of amyloid and tau proteins in the brain are thought to begin 10-20 years before the onset of overt symptoms (Hof et al., 1996; Perl, 2010; Bateman et al., 2012), suggesting that interventions designed to prevent accumulation of amyloid or other pathologic proteins may be more effective than attempting to reverse the pathology that already exists. However, for these early interventions to be successful, they need to be selectively administered to persons who will likely develop the disease in their lifetimes. Thus, it is critical to identify early biomarkers that are strongly predictive of future change in cognition.

Here, we investigate early changes in brain activity that occur before the initial onset of symptoms in those who go on to develop significant cognitive impairment $(\mathrm{CI})$. As regional cerebral blood flow (rCBF) is a marker of neuronal activity (Jueptner and Weiller, 1995), we used resting-state ${ }^{15} \mathrm{O}$-water PET data from participants in the Baltimore Longitudinal Study of Aging (BLSA) to examine longitudinal changes rCBF collected over a mean 7 year period in 22 participants who subsequently develop impairment in the years after the scan interval. We compare these changes with those that occur over the same period in 99 participants who remained cognitively normal.

The goal was to determine whether accelerated activity changes can be detected in the brains of those who develop future cognition dysfunction, and whether the distribution of these changes sheds light on the regional vulnerability of the brain before CI. Based on the regional distribution of early amyloid and 
Table 1. Group demographics

\begin{tabular}{lcc}
\hline & CN & Cl \\
\hline$N$ & $99(57$ male) & $22(11$ male) \\
Baseline age (yr) & $68.6(7.5)$ & $74.1(7.5)^{a}$ \\
Median age (yr) & 68.2 & 71.2 \\
Age range (yr) & $56.1-86.0$ & $61.0-85.0$ \\
Scan interval (yr) & $7.4(1.5)$ & $7.0(1.7)$ \\
Years to symptom onset & NA & $10.9(3.7)$ \\
Education (yr) & $16.3(2.7)$ & $16.4(3.0)$ \\
Hypertension (\%) & 46.5 & 63.6 \\
Diabetes (\%) & 10.1 & 13.6 \\
Hypothyroidism (\%) & 7.1 & 9.1 \\
APOE 3/4 (\%) & 21.2 & 22.7 \\
APOE 4/4 (\%) & 4.0 & 4.5 \\
\hline
\end{tabular}

${ }^{a}$ The cognitively impaired group is significantly older than the normal group $(p=0.002)$. No other differences between the groups were noted. NA, Not applicable.

tau pathology (Braak and Braak, 1991; Wolk and Klunk, 2009) and on the regional changes in brain activity noted in the prodromal mild cognitive impairment (MCI) stage of AD (de Leon et al., 2007; Pihlajamäki et al., 2009), we hypothesized that frontal, temporal, and parietal association cortices would be the most likely regions to exhibit altered activity levels before the onset of illness.

\section{Materials and Methods}

Participants. We used data from 121 older participants in the neuroimaging substudy (Resnick et al., 2000) of the BLSA (Shock et al., 1984) (Table 1) who had both MRI and PET imaging assessments for at least three annual visits. Of these participants, 99 (57 male, 42 female) remained cognitively normal $(\mathrm{CN})$ throughout the study. The remaining 22 (11 male, 11 female) participants were diagnosed with CI over time. CI was determined by consensus diagnosis using Diagnostic and Statistical Manual of Mental Disorders Third Edition, Revised (DSM-III-R) (1987) criteria for dementia, and the National Institute of Neurological and Communication Disorders-Alzheimer's Disease and Related Disorders Association criteria (McKhann et al., 1984), using neuropsychological diagnostic tests and clinical data (Driscoll et al., 2006). None of the participants had a history of CNS disease (epilepsy, stroke), psychiatric disorders, severe cardiac disease (myocardial infarction, coronary artery disease requiring angioplasty or bypass surgery), or metastatic cancer at enrollment.

The local Institutional Review Board approved the research protocol for this study, and written informed consent was obtained at each visit from all participants.

Neuropsychological testing. During each visit, participants completed a battery of 12 neuropsychological tests evaluating six cognitive domains. Memory was assessed using the California Verbal Learning Test and Benton Visual Retention Test (BVRT). Word knowledge and verbal ability were measured using Primary Mental Abilities Vocabulary. Verbal fluency was assessed by Letter (i.e., F, A, and S) and Category fluency tests. Attention and working memory were measured by the Digit Span Test of the Wechsler Adult Intelligence Scale-Revised and the Trail Making Test. Digits Backward, Trails B, and Verbal fluency (categories and letters) assessed executive function. The Card Rotations Test assessed visuospatial function. Neuropsychological testing occurred at each neuroimaging PET visit and continued during the years after the PET phase of the study.

PET scanning parameters. Annual PET scans were administered from baseline through year 8 of the study (Fig. 1). Valid scans for each participant were included in the analyses. In $\mathrm{CN}$ participants, scans were excluded from the point of diagnosis onward in those who developed significant health-related issues (stroke $n=3$, seizure disorder $n=1$, lymphoma $n=1$, aphasia $n=1$ ). Of the $22 \mathrm{CI}$, four had onset of CI before follow-up year 8 ( 1 individual had onset at year 5,2 individuals at year 6 , and 1 individual at year 7 of the study). We excluded scans on and after symptom onset in these individuals, so that data used in the analyses were only those collected before the onset of impairment. The follow-up scan interval examined in this study was $7.4 \pm 1.5$ years $($ mean \pm SD) for the $\mathrm{CN}$ group and $7.0 \pm 1.7$ years for the $\mathrm{CI}$ group. The mean time from baseline to onset of $\mathrm{CI}$ in the $\mathrm{CI}$ group was $10.9 \pm 3.7$ years.

Each PET session included a resting-state scan in which participants were instructed to keep their eyes open and focused on a computer screen covered by a black cloth. PET measures of rCBF were obtained using $\left[{ }^{15} \mathrm{O}\right]$ water. For each scan, $75 \mathrm{mCi}$ of $\left[{ }^{15} \mathrm{O}\right]$ water was injected as a bolus. Scans were performed on a GE 4096+ scanner, which provides 15 slices of $6.5 \mathrm{~mm}$ thickness. Images were acquired for $60 \mathrm{~s}$ from the time the total radioactivity counts in the brain reached threshold level. Attenuation correction was performed using a transmission scan acquired before the emission scans.

PET image preprocessing and mixed model analysis. Image preprocessing was done using Statistical Parametric Mapping (SPM5; Wellcome Department of Cognitive Neurology). For each participant across follow-up sessions, PET images were realigned to the first session, spatially normalized to the MNI template space with $2 \times 2 \times 2 \mathrm{~mm}$ resolution, and smoothed using a full width at half maximum of $12 \mathrm{~mm}$. Voxel rCBF values for all images were ratio adjusted and scaled to a mean global flow of $50 \mathrm{ml} / 100 \mathrm{~g} / \mathrm{min}$.

A mixed model approach was used to analyze the PET data, which enabled us to account for individual differences in longitudinal trends more effectively. The mixed model was implemented using $\mathrm{R}$ version 2.11.1 running the packages AnalyzeFMRI version 1.1-12 and lme4 version $0.999375-37$, and included fixed effects of age, sex, and group, and the interaction of each of these measures with change over time. The focus of the current analysis was the interaction between group ( $\mathrm{CN}$ vs $\mathrm{CI}$ ) and $\mathrm{rCBF}$ change over time, identifying brain regions that show significant differences in longitudinal rCBF changes between participants who retain normal cognition compared with those who develop subsequent CI. Baseline differences between the groups were also assessed. Whole-brain statistical contrast $t$-maps of group differences at baseline and differences in change over time (group $\times$ scan interval interaction) were generated using a statistical threshold of $p<0.005$ as recommended for PET data by the PET Working Group of the National Institutes of Health/NIA Neuroimaging Initiative (http://www.nia.nih.gov/about/ events/2011/positron-emission-tomography-working-group) with an additional cluster size threshold of $\geq 50$ voxels $\left(400 \mathrm{~mm}^{3}\right)$.

Because the two groups differed in baseline age, an age-matched sensitivity analysis was also performed in a subsample of participants using a 3:1 ratio of $\mathrm{CN}: \mathrm{CI}$ (CN age, $72.2 \pm 6.5$ years, mean $\pm \mathrm{SD}$; median age 69.9 years, range $61.3-85.9$ years; $\mathrm{CI}$ age $74.1 \pm 7.5$ years, median 71.2 years, range 61.0-85.0 years; no significant age difference between the groups, $p=0.25$ ).

To determine whether change in tissue volume of each region had an effect on the rCBF change in that area, we repeated all analyses with covariate adjustment for the longitudinal MRI volumes of each significant cluster observed in the mixed model results.

To further examine the changes in $\mathrm{rCBF}$ over time, $\mathrm{rCBF}$ values of significant regions in the voxel-based full sample analysis were extracted from a $4 \mathrm{~mm}$ spherical region centered on the local maxima of each area using the Marsbar SPM toolbox (Brett et al., 2002). Using the age- and sex-adjusted rCBF values, annual rates of change, direction of change, and characterization of the linear or nonlinear trajectory of rCBF change were then estimated for each region using a mixed model approach. These rCBF values were also used to examine the relationship between change in neuropsychological performance and change in $\mathrm{rCBF}$ over time. Here, the slope of performance change on each test was correlated with the slope of $\mathrm{rCBF}$ change from each region in the two groups.

MRI scanning. Scanning was performed on a GE Signa 1.5 Tesla scanner. A 3-D T1-weighted spoiled gradient refocused MRI scan $(35 \mathrm{~ms}$ TR, $5 \mathrm{~ms}$ TE, $24 \mathrm{~cm}$ FOV, $45^{\circ}$ flip angle, $256 \times 256$ matrix, $0.94 \times 0.94 \mathrm{~mm}$ voxel size, $1.5 \mathrm{~mm}$ slice thickness, 124 slices) was obtained annually at each imaging visit.

MRI volume calculation. The MRI scans were segmented into gray matter, white matter, and CSF and spatially normalized into stereotactic space using a high-dimensional elastic warping method (Davatzikos et al., 2001) and a volume-preserving transformation (Shen and Davatzikos, 2002). Binary maps of the clusters showing rCBF differences 
PET Scans

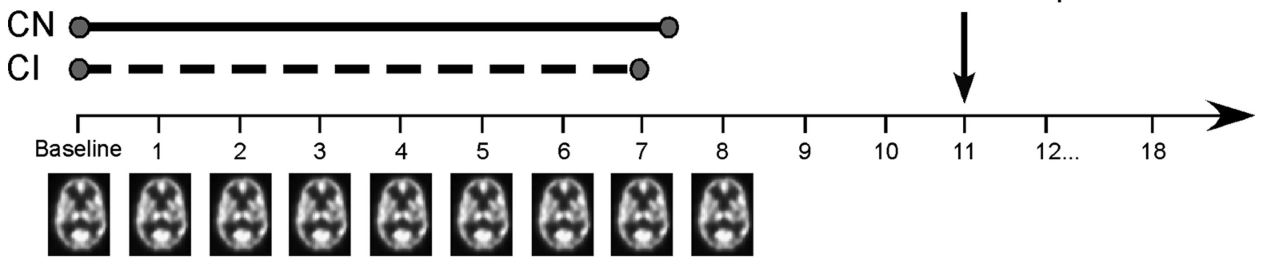

Years

Figure 1. Study design. In the initial phase of the neuroimaging study, annual resting-state PET scans were administered through follow-up year 8 of the study. Participants also performed a battery of cognitive tests each year. A group of participants developed initial symptoms of cognitive impairment on an average corresponding to year 11 (symptom onset, mean \pm SD, $10.9 \pm 3.7$ years from baseline; $n=22$ ). Changes in brain activity before the onset of impairment were assessed in Cl (scan interval examined, mean \pm SD, $7.0 \pm 1.7$ years) and compared with those who remained CN (scan interval examined, mean $\pm S D, 7.4 \pm 1.5$ years; $n=99$ ) throughout the study.

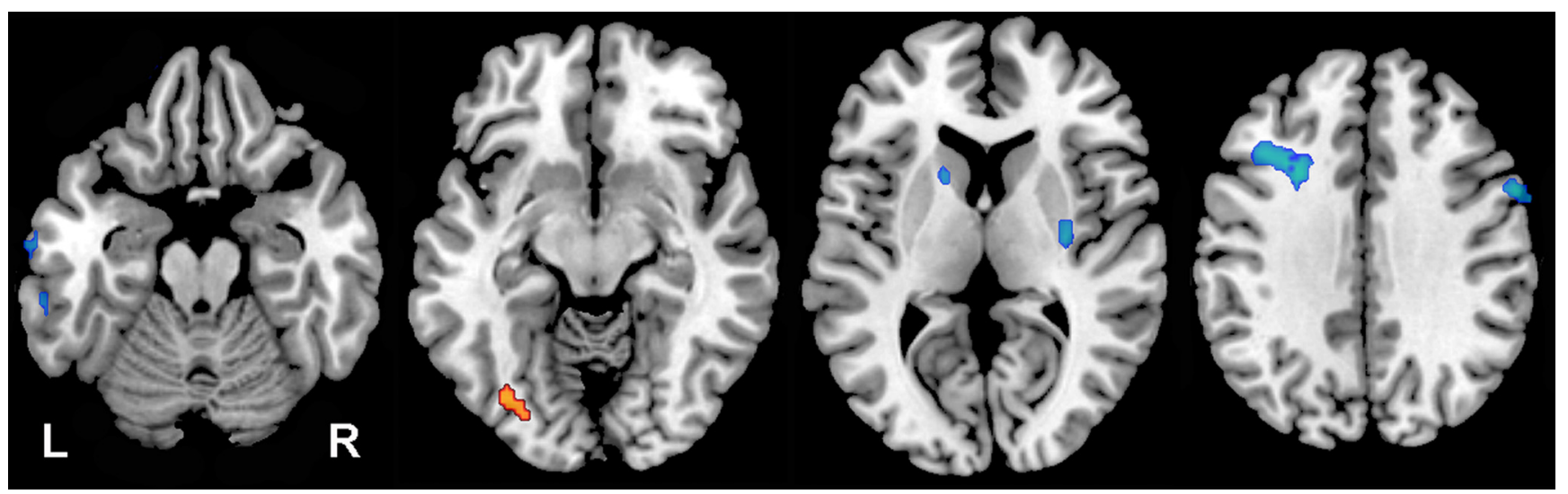

Figure 2. Group differences at baseline. Axial slices showing regions where the $\mathrm{Cl}$ group exhibited higher rCBF (red) and lower rCBF (blue) at the baseline assessment relative to the $\mathrm{CN}$ group. The higher rCBF in left occipital cortex (slice 2) and the lower rCBF in the right precentral gyrus (slice 4) did not remain significant after correction for MRI tissue volume.

between the two participant groups were generated from the PET analysis, and total volumes of gray + white matter were calculated within each cluster for each participant at each imaging visit. As described above, the volume of each cluster at each visit was then included as a covariate in the secondary PET analyses adjusting for tissue volume.

\section{Results}

\section{Neuropsychological testing}

Twenty-two participants received a clinical diagnosis of CI after the last PET CBF scan used in the current analysis. Nine participants were diagnosed with MCI, and 13 were diagnosed with Alzheimer's disease. In this group, the mean interval from baseline to onset of impairment for the CI group was 10.9 (3.7) years (range 4-15 years).

Linear mixed models were used to examine differences at baseline and in longitudinal change in task performance before the onset of impairment. Relative to $\mathrm{CN}$, the CI group performed similarly on most cognitive measures at baseline and in performance change over time. Differences were only noted on the Digit Span Test, where the CI group performed below the CN group on Digits Backwards at baseline $(\mathrm{CN}=7.9$ (0.2) digits, $\mathrm{CI}=6.8(0.4)$ digits; $p=0.02)$ and showed a decline in Digits Forward performance over time $(\mathrm{CN}=0.02$ slope of change, $\mathrm{CI}=-0.08$ slope; $p=0.03$ ).

\section{Baseline differences in $\mathrm{rCBF}$}

Significant differences were noted at baseline between the CI and $\mathrm{CN}$ groups (Fig. 2). Higher rCBF was noted in the middle occipital gyrus (BA 19, $p<0.001$ ) in the CI relative to the CN group.
Lower $\mathrm{CCBF}$ in the $\mathrm{CI}$ group was seen in the middle frontal gyrus (BA 9, $p<0.001$ ), precentral gyrus (BA $4, p<0.001$ ), inferior temporal gyrus (BA 20, $p<0.001)$, caudate $(p<0.001)$, and putamen $(p=0.001)$. Of these baseline differences, only decreased rCBF noted in middle frontal gyrus, inferior temporal gyrus, caudate, and putamen survived correction for regional MRI volume.

\section{Longitudinal differences in $\mathrm{rCBF}$}

We found significant differences in longitudinal rCBF change between the $\mathrm{CI}$ and $\mathrm{CN}$ groups (Fig. 3; Table 2). Several regions exhibited greater increases in rCBF over time in the CI compared with $\mathrm{CN}$ group. These areas primarily involved the frontal lobe and included orbitofrontal (BA 11) and medial frontal (BA 10) regions, extending into the anterior cingulate cortex (BA 32). Areas of accelerated rCBF decrease in CI compared with $\mathrm{CN}$ included the insula, supramarginal gyrus (BA 40), medial inferior parieto-occipital cortex (BA 18), lingual gyrus (BA 18), and thalamus. The brainstem also appeared as a region of decreased $\mathrm{rCBF}$, but this difference was the result of a reduced increase in rCBF over time in CI relative to $\mathrm{CN}$. All of the regions survived regional MRI volume correction, except the insula, which was no longer significant after correction.

Shape analysis of the trajectories of longitudinal rCBF change showed no significant nonlinear changes over time, suggesting that all of the changes were linear in nature (Fig. 4). The annual rates of change and the effective direction of change for each region are shown in Table 3. 


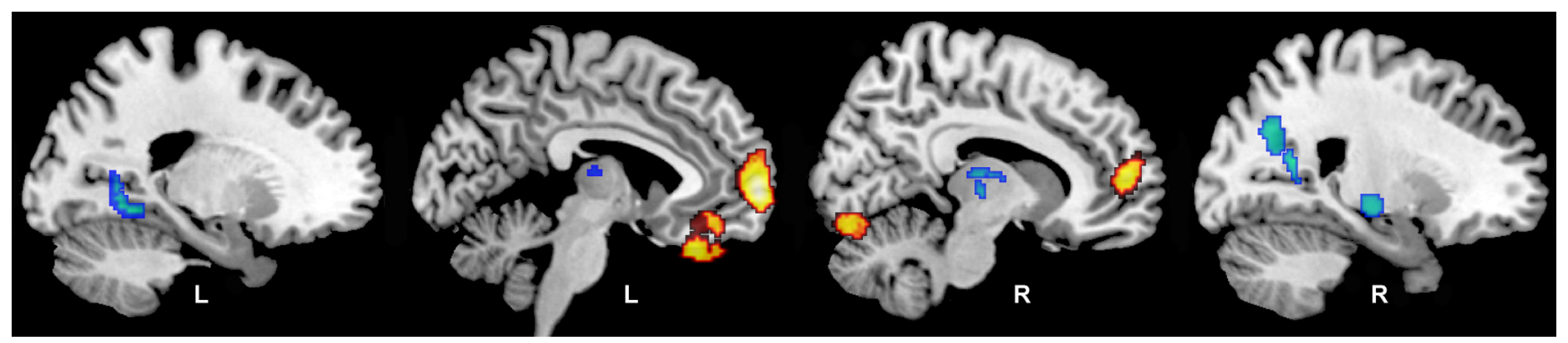

Figure 3. Longitudinal changes in rCBF. Regions showing differences in longitudinal rates of rCBF changes for the $\mathrm{Cl}$ group relative to the $\mathrm{CN}$ group are shown on sagittal sections of the brain. Areas in yellow represent regions where $\mathrm{Cl}$ show greater increases in $\mathrm{rCBF}$ over time relative to $\mathrm{CN}$; areas in blue represent regions where $\mathrm{Cl}$ exhibit greater decreases in rCBF over time. The group difference in insular decline (slice 4) did not remain significant after MRI tissue volume correction.

\section{Table 2. Local maxima of rCBF change over time ${ }^{a}$}

\begin{tabular}{llrrrrl}
\hline Region & Side & $x$ & $y$ & $z$ & $p$ & Voxels \\
\hline Greater rCBF increases & & & & & & \\
$\quad$ Orbitofrontal cortex (11) & $\mathrm{L}$ & -4 & 32 & -28 & $<0.001$ & 413 \\
$\quad$ Medial frontal gyrus (10) & $\mathrm{L}$ & -6 & 64 & 0 & $<0.001$ & $789^{b}$ \\
$\quad$ Anterior cingulate cortex (32) & $\mathrm{R}$ & 8 & 54 & 8 & $<0.001$ & $789^{b}$ \\
$\quad$ Cerebellum & $\mathrm{R}$ & 12 & -78 & -16 & $<0.001$ & 138 \\
Greater rCBF decreases & & & & & & \\
$\quad$ Insula & $\mathrm{R}$ & 66 & 10 & 2 & 0.002 & $65^{c, d}$ \\
$\quad$ Supramarginal gyrus (40) & $\mathrm{R}$ & 64 & -38 & 32 & 0.003 & $59^{d}$ \\
Parieto-occipital cortex (18) & $\mathrm{R}$ & 22 & -62 & 36 & $<0.001$ & 291 \\
$\quad$ Lingual gyrus (18) & $\mathrm{L}$ & -20 & -54 & -2 & $<0.001$ & 105 \\
$\quad$ Thalamus & $\mathrm{R}$ & 6 & -10 & 8 & 0.003 & 59 \\
$\quad$ Brainstem & $\mathrm{R}$ & 18 & -22 & -8 & $<0.001$ & 154 \\
\hline
\end{tabular}

${ }^{a}$ Regions where Cl show differences in longitudinal rCBF change compared with CN in the full sample of participants. Stereotaxic coordinates are listed; Brodmann areas are indicated in parentheses.

${ }^{b}$ Regions contained within the same cluster.

'Region that did not survive correction for tissue volume change over time.

${ }^{d}$ Regions that were no longer significant in the age-matched analysis.

\section{Age-matched analysis}

The results of the age-matched analyses were similar to those observed with the full sample. The only difference between the findings of the age-matched sample and the full sample was a lack of significant longitudinal $\mathrm{rCBF}$ decline in the insula and supramarginal gyrus (BA 40) of the age-matched CI relative to the $\mathrm{CN}$ groups (denoted in Table 2).

\section{Neuropsychological performance and change in $\mathrm{rCBF}$}

Correlations of the change in test performance and the change in rCBF revealed only one significant relationship. Increased errors over time on the BVRT correlated negatively with orbitofrontal rCBF in the CN group $(r=-0.23, p=0.02)$ and positively with orbitofrontal $\mathrm{rCBF}$ in the CI group $(r=0.43, p=0.04)$. This suggests that, over time, poorer performance (increased BVRT errors) was related to the decreased rCBF observed in the $\mathrm{CN}$ group and to the increased $\mathrm{rCBF}$ observed in the $\mathrm{CI}$ group within this region (trajectory of orbitofrontal $\mathrm{rCBF}$ change shown in Fig. 4).

\section{Discussion}

Using longitudinal neuroimaging data from the BLSA, we have shown that people who subsequently develop CI show accelerated changes in brain activity that begin years before the onset of symptoms. These changes include both relative increases in activity over time in frontal regions and decreases in activity in temporal and parietal areas thought to be critical for different aspects of cognition. The changes are also found within re- gions that show early accumulation of pathology in Alzheimer's disease.

Many of the group differences in change over time were located in the frontal lobe of the brain, with each area exhibiting accelerated linear increases in activity over time in the CI compared with CN group. These regions included orbitofrontal, medial frontal, and anterior cingulate cortex. Past studies have shown that the orbitofrontal cortex and anterior cingulate regions are critical for attention and error detection (Petrides, 2007; Tang et al., 2012), and the medial frontal cortex is thought to play a role in memory processes (Burgess et al., 2011). These regions, particularly the medial frontal and anterior cingulate cortex, are additionally considered to be central components of the default mode network (Shulman et al., 1997; Raichle et al., 2001), the modulation of which is theorized to impact normal cognitive function with advancing age (Lustig et al., 2003; Grady et al., 2006).

Other regions exhibited accelerated linear decreases in activity over time in the CI compared with the $\mathrm{CN}$ group. These included the lingual gyrus and the medial inferior parieto-occipital cortex. The lingual gyrus, which lies along the ventral occipitotemporal visual pathway, and the medial inferior parietal cortex are areas also thought to be involved in memory and attention processes (Cabeza et al., 2012; Straube, 2012). These results, in conjunction with the longitudinal increases in frontal activity, suggest that brain activity changes begin long before the onset of CI in regions that are ultimately crucial for maintenance of cognitive function.

Baseline differences between the groups were also observed in middle frontal and inferior temporal cortices implicated in memory processes (Haxby et al., 2000; Axmacher et al., 2008). Yet, these areas were relatively small in size and did not show significant differences between groups in activity change over time. The lack of baseline differences in the areas that do show differential changes over time may be the result of interindividual variability in $\mathrm{rCBF}$ and the limited power available when examining a single point in time.

Our findings of accelerated longitudinal changes in brain activity in individuals who develop CI support findings from crosssectional resting-state studies in MCI. Although activity in the default mode network is thought to generally decrease in MCI and $\mathrm{AD}$ with advancing disease state (Lustig et al., 2003; Greicius and Menon, 2004; Petrella et al., 2007; Pihlajamäki et al., 2010), some studies have shown an increase in medial frontal regions in MCI relative to cognitively normal individuals (Wang et al., 2011; De Vogelaere et al., 2012; Jin et al., 2012). It is particularly interesting that the activity levels in the frontal cortex appear to be positively related to the accumulation of $\beta$-amyloid in the brain (Sperling et al., 2009) and that increased connectivity of frontal 
regions with other brain areas occurs in asymptomatic individuals at high risk of developing AD (Fleisher et al., 2009). A number of studies have also shown decreased resting-state activity levels within the posterior cingulate and parietal cortex in MCI relative to normal agers (Sorg et al., 2007; De Vogelaere et al., 2012; Wang et al., 2011). Our results confirm the findings seen in individuals with MCI and suggest that resting-state activity levels within these regions begin to change years before the diagnosis of CI. Indeed, anterior cingulate, medial frontal, and supramarginal regions showed significantly different activity levels between the impaired and normal groups at the last follow-up visit, which occurred $\sim 4$ years before symptom onset in those who subsequently developed impairment.

The next question naturally relates to what these changes represent. Here, we see regions of both accelerated decreases and increases in $\mathrm{rCBF}$ activity levels over time in association with CI. Declines in rCBF likely represent regions of increased functional vulnerability over time, whereas increases in $\mathrm{rCBF}$ are more challenging to explain. Historically, increases in activity in the older brain have been interpreted as representing compensatory processes (Grady et al., 1999; Madden et al., 1999). That is, one region increases activity levels to compensate for failing activity in other region(s), allowing for the maintenance of cognitive function. Here, we see some evidence in support of this theory. Despite our two groups having similar longitudinal trajectories of cognitive performance during the studied interval, declining performance on a test of visual memory recall, the BVRT, was associated with declining activity in the $\mathrm{CN}$ group and with increasing activity in the CI group.

Other explanations of increasing activity in $\mathrm{AD}$ and its prodromal stage have also been proposed (Palop and Mucke, 2010; Reiman and Jagust, 2012). It is possible that increases in brain activity represent an excitotoxic reaction to increasing neuropathology (Sojkova et al., 2008; Sperling et al., 2009; Bakker, 2012), which may ultimately result in further synaptic and network dysfunction (Kapogiannis and Mattson, 2011). It is also possible that increases represent a failure to properly inhibit activity levels (Andrews-Zwilling et al., 2010), again likely related to the development of neuropathology.

It is well known that there is a characteristic progression of pathology in the brain of $\mathrm{AD}$ patients and that hallmark features of the disease involve the abnormal accumulation of amyloid and tau proteins in the brain. It is thought that abnormal accumulation of these proteins begins 10-20 years before the onset of cognitive dysfunction (Hof et al., 1996; Perl, 2010), although Braak and Braak (1995) have suggested that some changes may begin as early as 50 years before the end stage of the disease.

With respect to amyloid deposition, autopsy studies have shown that there is accumulation first in orbitofrontal, temporal pole, and inferior temporal areas, with further accumulation in frontal, occipital, and inferior parietal areas in the early stages of disease progression (Braak and Braak, 1991; Thal et al., 2002). In were linear in nature.
Orbitofrontal Cortex

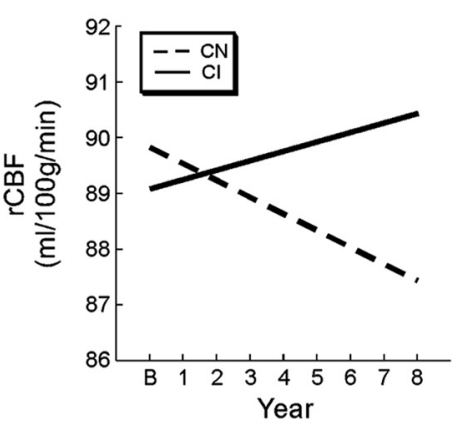

Lingual Gyrus

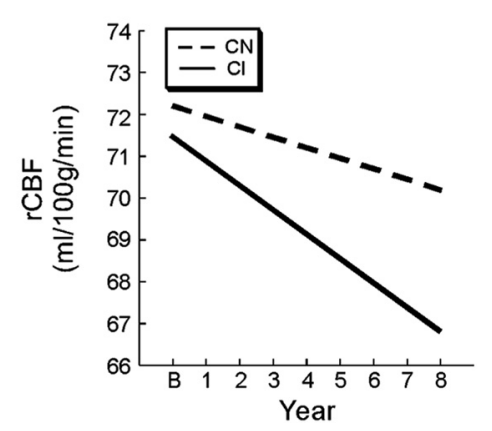

.

Figure 4. Regional trajectories of $\mathrm{rCBF}$ change. The $\mathrm{Cl}$ group shows different trajectories of $\mathrm{rCBF}$ of change over time relative to the $\mathrm{CN}$ group. Estimated trajectories of longitudinal change are shown for regions of greater $\mathrm{rCBF}$ increase in the Cl group (orbitofrontal and anterior cingulate regions) and greater rCBF decrease in the CI group (parieto-occipital and lingual regions). All changes

Table 3. Rates of rCBF change over time ${ }^{a}$

\begin{tabular}{|c|c|c|c|c|c|}
\hline & \multicolumn{2}{|c|}{ Baseline rCBF } & \multicolumn{2}{|c|}{$\begin{array}{l}\text { Annual rate of } \\
\text { change }\end{array}$} & \multirow[b]{2}{*}{ Effective change } \\
\hline & $\mathrm{CN}$ & $\mathrm{Cl}$ & $\mathrm{CN}$ & Cl & \\
\hline \multicolumn{6}{|l|}{ Greater rCBF increases } \\
\hline Orbitofrontal cortex (11) & $75.17(7.0)$ & $74.33(8.4)$ & -0.35 & 0.18 & Increase in Cl \\
\hline Medial frontal gyrus (10) & $75.97(4.5)$ & $74.81(5.2)$ & -0.36 & 0.19 & Increase in Cl \\
\hline Anterior cingulate cortex (32) & $89.83(5.3)$ & $89.08(5.7)$ & -0.30 & 0.17 & Increase in Cl \\
\hline Cerebellum & $96.81(7.1)$ & $97.36(7.9)$ & -0.43 & 0.14 & Increase in $\mathrm{Cl}$ \\
\hline \multicolumn{6}{|l|}{ Greater rCBF decreases } \\
\hline Insula & $41.60(8.5)$ & $39.93(8.5)$ & -0.22 & -0.82 & Greater decrease in C \\
\hline Supramarginal gyrus (40) & $81.32(4.5)$ & $81.38(5.3)$ & 0.00 & -0.38 & Greater decrease in C \\
\hline Parieto-occipital cortex (18) & $72.72(6.1)$ & $71.99(6.0)$ & 0.04 & -0.24 & Greater decrease in C \\
\hline Lingual gyrus (18) & $72.21(8.3)$ & $71.54(14.0)$ & -0.25 & -0.59 & Greater decrease in C \\
\hline Thalamus & $78.62(8.6)$ & $76.78(11.8)$ & -0.70 & -1.03 & Greater decrease in C \\
\hline Brainstem & $84.15(5.4)$ & $84.59(6.9)$ & 0.42 & 0.09 & Less increase in Cl \\
\hline
\end{tabular}

${ }^{a}$ Annual rates of $\mathrm{rCBF}$ change and the effective direction of change for regions showing significant differences in longitudinal change between the $\mathrm{CN}$ and $\mathrm{Cl}$ groups in Table 2. Baseline rCBF was not significantly different between the groups.

vivo neuroimaging tracers also show early accumulation of fibrillar amyloid in orbitofrontal and parietal regions of the brain (Wolk and Klunk, 2009). The orbitofrontal, medial frontal, inferior temporal, and inferior parieto-occipital brain areas that show accelerated change in CI in the present study are located within the regional pattern of early amyloid deposition.

Overlap between regions of CI-associated accelerated blood flow change is also seen in relation to the distribution of abnormally phosphorylated tau protein in the form of neurofibrillary tangles. Neurofibrillary tangles generally first develop in the entorhinal cortex and then progress to inferior temporal, inferior frontal, and retrosplenial cortex (Braak and Braak, 1995, 1997). Accelerated CI-associated brain activity changes noted in orbito- 
frontal, medial frontal, and inferior temporal cortex fall within the areas vulnerable to early tau accumulation.

Together, the majority of regions showing accelerated $\mathrm{rCBF}$ change in CI compared with $\mathrm{CN}$ involve areas of early neuropathologic changes in $\mathrm{AD}$, suggesting that there may be a connection between early pathologic change and early changes in brain activity. Although the exact mechanism(s) responsible for the activity changes remains to be determined, our results show that there are significant changes in brain function that precede the development of CI. In the face of accumulating neuropathology, an argument could be made that some of these changes represent compensatory activity that support the maintenance of cognitive function and that impairment began after the early compensatory mechanisms ultimately failed.

Our findings also point to a limitation of cross-sectional studies of cognitively "normal" individuals. These samples are typically comprised of both individuals who are in a preclinical stage of disease as well as those who will maintain normal cognition. This makes separation of the two groups difficult when examining a single point in time. Longitudinal studies are more likely to discern the clinical course of participants and are therefore critical in developing the tools needed to target individuals who will benefit from disease intervention therapies before their symptoms become apparent and possibly irreversible.

\section{References}

Alzheimer's Association (2012) Alzheimer's disease facts and figures. Alzheimers Dement 8:131-168. CrossRef Medline

Andrews-Zwilling Y, Bien-Ly N, Xu Q, Li G, Bernardo A, Yoon SY, Zwilling D, Yan TX, Chen L, Huang Y (2010) Apolipoprotein E4 causes age- and Tau-dependent impairment of GABAergic interneurons, leading to learning and memory deficits in mice. J Neurosci 30:13707-13717. CrossRef Medline

Axmacher N, Schmitz DP, Wagner T, Elger CE, Fell J (2008) Interactions between medial temporal lobe, prefrontal cortex, and inferior temporal regions during visual working memory: a combined intracranial EEG and functional magnetic resonance imaging study. J Neurosci 28:7304-7312. CrossRef Medline

Bakker A, Krauss GL, Albert MS, Speck CL, Jones LR, Stark CE, Yassa MA, Bassett SS, Shelton AL, Gallagher M (2012) Reduction of hippocampal hyperactivity improves cognition in amnestic mild cognitive impairment. Neuron 74:467-474. CrossRef Medline

Bateman RJ, Xiong C, Benzinger TL, Fagan AM, Goate A, Fox NC, Marcus DS, Cairns NJ, Xie X, Blazey TM, Holtzman DM, Santacruz A, Buckles V, Oliver A, Moulder K, Aisen PS, Ghetti B, Klunk WE, McDade E, Martins $\mathrm{RN}$, et al. (2012) Clinical and biomarker changes in dominantly inherited Alzheimer's disease. N Engl J Med 367:795-804. CrossRef Medline

Braak H, Braak E (1991) Neuropathological stageing of Alzheimer-related changes. Acta Neuropathol 82:239-259. CrossRef Medline

Braak H, Braak E (1995) Staging of Alzheimer's disease-related neurofibrillary changes. Neurobiol Aging 16:271-278; discussion 278-284. Medline

Braak H, Braak E (1997) Pattern of cortical lesions in Alzheimer's disease. In: Alzheimer's disease: biology, diagnosis and therapeutics (Iqbal K, Winbald B, Nishimura T, Takeda M, Wisniewski H, eds), pp 227-237. Chicago: Wiley.

Brett M, Anton J, Valabregue R, Poline J (2002) Region of interest analysis using an SPM toolbox. Neuroimage 16:1140-1141.

Burgess PW, Gonen-Yaacovi G, Volle E (2011) Functional neuroimaging studies of prospective memory: what have we learnt so far? Neuropsychologia 49:2246-2257. CrossRef Medline

Cabeza R, Ciaramelli E, Moscovitch M (2012) Cognitive contributions of the ventral parietal cortex: an integrative theoretical account. Trends Cogn Sci 16:338-352. CrossRef Medline

Callaway E (2012) Alzheimer's drugs take a new tack. Nature 498:13-14. Medline

Castellani RJ, Perry G (2012) Pathogenesis and disease-modifying therapy in Alzheimer's disease: the flat line of progress. Arch Med Res 43:694698. CrossRef Medline

Davatzikos C, Genc A, Xu D, Resnick SM (2001) Voxel-based morphome- try using the RAVENS maps: methods and validation using simulated longitudinal atrophy. Neuroimage 14:1361-1369. CrossRef Medline

de Leon MJ, Mosconi L, Blennow K, DeSanti S, Zinkowski R, Mehta PD, Pratico D, Tsui W, Saint Louis LA, Sobanska L, Brys M, Li Y, Rich K, Rinne J, Rusinek H (2007) Imaging and CSF studies in the preclinical diagnosis of Alzheimer's disease. Ann N Y Acad Sci 1097:114-145. CrossRef Medline

De Vogelaere F, Santens P, Achten E, Boon P, Vingerhoets G (2012) Altered default-mode network activation in mild cognitive impairment compared with healthy aging. Neuroradiology 54:1195-1206. CrossRef Medline

Driscoll I, Resnick SM, Troncoso JC, An Y, O’Brien R, Zonderman AB (2006) Impact of Alzheimer's pathology on cognitive trajectories in nondemented elderly. Ann Neurol 60:688-695. CrossRef Medline

Fleisher AS, Sherzai A, Taylor C, Langbaum JB, Chen K, Buxton RB (2009) Resting-state BOLD networks versus task-associated functional MRI for distinguishing Alzheimer's disease risk groups. Neuroimage 47:16781690. CrossRef Medline

Grady CL, McIntosh AR, Rajah MN, Beig S, Craik FI (1999) The effects of age on the neural correlates of episodic encoding. Cereb Cortex 9:805-814. CrossRef Medline

Grady CL, Springer MV, Hongwanishkul D, McIntosh AR, Winocur G (2006) Age-related changes in brain activity across the adult lifespan. J Cogn Neurosci 18:227-241. CrossRef Medline

Greicius MD, Menon V (2004) Default-mode activity during a passive sensory task: uncoupled from deactivation but impacting activation. J Cogn Neurosci 16:1484-1492. CrossRef Medline

Haxby JV, Petit L, Ungerleider LG, Courtney SM (2000) Distinguishing the functional roles of multiple regions in distributed neural systems for visual working memory. Neuroimage 11:380-391. CrossRef Medline

Hof PR, Giannakopoulos P, Bouras C (1996) The neuropathological changes associated with normal brain aging. Histol Histopathol 11:10751088. Medline

Jin M, Pelak VS, Cordes D (2012) Aberrant default mode network in subjects with amnestic mild cognitive impairment using resting-state functional MRI. Magn Reson Imaging 30:48-61. CrossRef Medline

Jueptner M, Weiller C (1995) Does measurement of regional cerebral blood flow reflect synaptic activity? Implications for PET and fMRI. Neuroimage 2:148-156. CrossRef Medline

Kapogiannis D, Mattson MP (2011) Disrupted energy metabolism and neuronal circuit dysfunction in cognitive impairment and Alzheimer's disease. Lancet Neurol 10:187-198. CrossRef Medline

Lustig C, Snyder AZ, Bhakta M, O’Brien KC, McAvoy M, Raichle ME, Morris JC, Buckner RL (2003) Functional deactivations: change with age and dementia of the Alzheimer type. Proc Natl Acad Sci U S A 100:1450414509. CrossRef Medline

Madden DJ, Gottlob LR, Allen PA (1999) Adult age differences in visual search accuracy: attentional guidance and target detectability. Psychol Aging 14:683-694. CrossRef Medline

McKhann G, Drachman D, Folstein M, Katzman R, Price D, Stadlan EM (1984) Clinical diagnosis of Alzheimer's disease: report of the NINCDSADRDA Work Group under the auspices of Department of Health and Human Services Task Force on Alzheimer's Disease. Neurology 34:939_ 944. Medline

Palop JJ, Mucke L (2010) Amyloid-beta-induced neuronal dysfunction in Alzheimer's disease: from synapses toward neural networks. Nat Neurosci 13:812-818. CrossRef Medline

Perl DP (2010) Neuropathology of Alzheimer's disease. Mt Sinai J Med 77: 32-42. CrossRef Medline

Petrella JR, Prince SE, Wang L, Hellegers C, Doraiswamy PM (2007) Prognostic value of posteromedial cortex deactivation in mild cognitive impairment. PLoS One 2:e1104. CrossRef Medline

Petrides M (2007) The orbitofrontal cortex: novelty, deviation from expectation, and memory. Ann N Y Acad Sci 1121:33-53. CrossRef Medline

Pihlajamäki M, Jauhiainen AM, Soininen H (2009) Structural and functional MRI in mild cognitive impairment. Curr Alzheimer Res 6:179-185. CrossRef Medline

Pihlajamäki M, O'Keefe K, Bertram L, Tanzi RE, Dickerson BC, Blacker D, Albert MS, Sperling RA (2010) Evidence of altered posteromedial cortical fMRI activity in subjects at risk for Alzheimer disease. Alzheimer Dis Assoc Disord 24:28-36. CrossRef Medline 
Raichle ME, MacLeod AM, Snyder AZ, Powers WJ, Gusnard DA, Shulman GL (2001) A default mode of brain function. Proc Natl Acad Sci U S A 98:676-682. CrossRef Medline

Reiman EM, Jagust WJ (2012) Brain imaging in the study of Alzheimer's disease. Neuroimage 61:505-516. CrossRef Medline

Resnick SM, Goldszal AF, Davatzikos C, Golski S, Kraut MA, Metter EJ, Bryan $\mathrm{RN}$, Zonderman AB (2000) One-year age changes in MRI brain volumes in older adults. Cereb Cortex 10:464-472. CrossRef Medline

Shen D, Davatzikos C (2002) HAMMER: hierarchical attribute matching mechanism for elastic registration. IEEE Trans Med Imaging 21:14211439. CrossRef Medline

Shock NW, Greulich RC, Andres R, Arenberg D, Costa PT Jr, Lakatta E, Tobin JD (1984) Normal human aging: the Baltimore Longitudinal Study of Aging. Washington, DC: U.S. Government Printing Office.

Shulman GL, Fiez JA, Corbetta M, Buckner RL, Miezin FM, Raichle ME, Petersen SE (1997) Common blood flow changes across visual tasks: II. Decreases in cerebral cortex. J Cogn Neurosci 9:648-663. CrossRef Medline

Sojkova J, Beason-Held L, Zhou Y, An Y, Kraut MA, Ye W, Ferrucci L, Mathis CA, Klunk WE, Wong DF, Resnick SM (2008) Longitudinal cerebral blood flow and amyloid deposition: an emerging pattern? J Nucl Med 49:1465-1471. CrossRef Medline

Sorg C, Riedl V, Mühlau M, Calhoun VD, Eichele T, Läer L, Drzezga A, Förstl H, Kurz A, Zimmer C, Wohlschläger AM (2007) Selective changes of resting-state networks in individuals at risk for Alzheimer's disease. Proc Natl Acad Sci U S A 104:18760-18765. CrossRef Medline

Sperling RA, Laviolette PS, O'Keefe K, O’Brien J, Rentz DM, Pihlajamäki M, Marshall G, Hyman BT, Selkoe DJ, Hedden T, Buckner RL, Becker JA, Johnson KA (2009) Amyloid deposition is associated with impaired default network function in older persons without dementia. Neuron 63: 178-188. CrossRef Medline

Straube B (2012) An overview of the neuro-cognitive processes involved in the encoding, consolidation, and retrieval of true and false memories. Behav Brain Funct 8:35. CrossRef Medline

Tang YY, Rothbart MK, Posner MI (2012) Neural correlates of establishing, maintaining, and switching brain states. Trends Cogn Sci 16:330-337. CrossRef Medline

Thal DR, Rüb U, Orantes M, Braak H (2002) Phases of A beta-deposition in the human brain and its relevance for the development of AD. Neurology 58:1791-1800. CrossRef Medline

Wang Z, Yan C, Zhao C, Qi Z, Zhou W, Lu J, He Y, Li K (2011) Spatial patterns of intrinsic brain activity in mild cognitive impairment and Alzheimer's disease: a resting-state functional MRI study. Hum Brain Mapp 32:1720-1740. CrossRef Medline

Wolk DA, Klunk W (2009) Update on amyloid imaging: from healthy aging to Alzheimer's disease. Curr Neurol Neurosci Rep 9:345-352. CrossRef Medline 